\title{
Clinical Significance of an Alloantibody against the Kell Blood Group Glycoprotein
}

\author{
Stella Maris Mattaloni ${ }^{a, b}$ Carine Arnonic Rosario Céspedes ${ }^{d} \quad$ Claudia Nonaka $^{e}$ \\ Carolina Trucco Boggione ${ }^{a, b}$ Melina Eliana Luján Brajovich ${ }^{a, b} \quad$ Andrea Trejo $^{d} \quad$ Néstor Zani $^{\mathrm{e}}$ \\ Claudia Silvia Biondi ${ }^{b}$ Lilian Castilho ${ }^{f}$ Carlos Miquel Cotorruelo ${ }^{a, b}$ \\ a IDICER-CONICET, Rosario, Argentina;

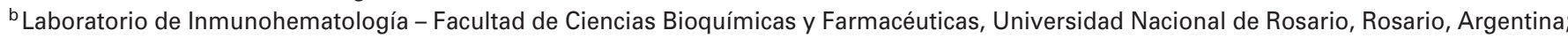 \\ ${ }^{c}$ Colsan-Associaçao Beneficente de Coleta de Sangue, Sao Paulo, Brazil; \\ ${ }^{\mathrm{d}}$ Hospital Zonal General de Agudos Dr. Carlos Bocalandro, Buenos Aires, Argentina; \\ e Hospital Nacional Profesor Alejandro Posadas, Buenos Aires, Argentina; \\ ${ }^{\mathrm{f}}$ Hemocentro - Unicamp, Campinas, Brazil
}

\section{Keywords}

Kell blood group system - Anti-Ku alloantibody .

Hemolytic disease of the fetus and newborn .

$\mathrm{K}_{0}$ phenotype $\cdot$ Kell null phenotype $\cdot$ Alloimmunization

\section{Summary}

Background: Kell null $\left(\mathrm{K}_{0}\right)$ individuals can produce anti-Ku, an antibody against many epitopes in the Kell glycoprotein, after transfusion and/or pregnancy. Since sensitized $\mathrm{K}_{0}$ patients are rare, little is known about anti-Ku clinical relevance and in particular about its association to hemolytic disease of the fetus and newborn. Case Report: This work describes a case of neonatal hyperbilirubinemia due to immune-mediated erythrocyte destruction by an alloantibody directed against the Kell glycoprotein. Serologic and molecular approaches identified an anti-Ku alloantibody in maternal serum. A homozygous IVS3 + 1g>a point mutation ( $K E L^{*} 02 \mathrm{~N} .06$ allele) was found to be responsible for the lack of Kell antigen expression in the mother's red blood cell and subsequent alloimmunization after a previous pregnancy. Even though in most cases Kell antibodies are clinically severe and may cause suppression of erythropoiesis, in our case the newborn had a moderate anemia and hyperbilirubinemia that was successfully treated with phototherapy without requiring exchange transfusion. Serological and molecular studies performed in the proband's family members allowed us to provide them with proper counseling regarding alloimmunization after transfusion and/or pregnancy. Conclusions: This case enlarges the understanding of the clinical significance of alloantibodies against Kell blood group antigens.

(c) 2016 S. Karger GmbH, Freiburg

\section{Introduction}

The Kell system (ISBT 006) is one of the most important blood groups in transfusion and obstetric medicine. It is highly immunogenic, and Kell antibodies are considered clinically significant. The Kell blood group system comprises 35 antigens, of which $\mathrm{K} / \mathrm{k}$ (KEL1/KEL2), $\mathrm{Kp}^{\mathrm{a}} / \mathrm{Kp}^{\mathrm{b}}$ (KEL3/KEL4), and $\mathrm{Js}^{\mathrm{a}} / \mathrm{Js}^{\mathrm{b}}$ (KEL6/KEL7) are the most important. The expression of Kell antigens is determined by different alleles of the KEL gene which is organized into 19 exons. Single nucleotide polymorphisms are the most common cause of different Kell phenotypes. Kell antigens are expressed on the type II Kell glycoprotein which spans the red blood cell (RBC) membrane once and is linked through a single disulfide bond to the XK protein, an integral membrane polypeptide that expresses the $\mathrm{Kx}$ blood group antigen (XK1). The absence of XK protein leads to the Mc Leod syndrome that is characterized by neuromuscular abnormalities, mild hemolysis, and RBCs acanthocytosis with a greatly reduced amount of the Kell protein and all of its antigens (Mc Leod phenotype) [1, 2].

Nucleotide changes that occur in the KEL gene may give raise to silent alleles ( $K_{0}$ alleles) responsible for the lack of Kell antigen expression, the so-called Kell null phenotype ( $K_{0}$ phenotype). Currently, at least 37 different $K_{0}$ alleles in a scarce number of individuals have been recognized to abolish Kell antigen expression when carried in homozygosity or compound heterozygosity. In addition, several nucleotide changes affecting the KEL gene lead to depressed or weak Kell antigens, which is termed $\mathrm{K}_{\text {mod }}$ phenotype [3-5].

Lack of Kell glycoprotein in $\mathrm{K}_{0}$ individuals does not result in a recognizable illness; however, they can produce anti-Ku (antiKEL5), an antibody against many epitopes in the whole polypeptide, after transfusion and/or pregnancy. Since sensitized $\mathrm{K}_{0}$ patients are rare, little is known about anti-Ku clinical relevance and

\section{KARGER}

() 2017 S. Karger GmbH, Freiburg 
Table 1. Evolution and laboratory findings of the newborn during hospitalization

\begin{tabular}{|c|c|c|c|c|c|}
\hline & Day 1 & Day 2 & Day 3 & Day 4 & Day 5 \\
\hline Total bilirubin, mg/dl & $\begin{array}{l}6.32 \\
7.80\end{array}$ & $\begin{array}{l}9.84 \\
20.5 \\
21.16\end{array}$ & $\begin{array}{l}22.45 \\
23.54 \\
18.00 \\
13.40 \\
13.10\end{array}$ & 9.9 & 9.8 \\
\hline Hematocrit, \% & 59 & 47 & $\begin{array}{l}46 \\
42 \\
39\end{array}$ & 36 & 34 \\
\hline Hemoglobin, g/dl & 17.0 & 14.7 & 12.2 & 11.3 & 11.0 \\
\hline Cardiological evaluation & $\begin{array}{l}\text { hemodynamically } \\
\text { stable }\end{array}$ & $\begin{array}{l}\text { hemodynamically } \\
\text { stable }\end{array}$ & $\begin{array}{l}\text { hemodynamically } \\
\text { stable }\end{array}$ & $\begin{array}{l}\text { hemodynamically } \\
\text { stable }\end{array}$ & $\begin{array}{l}\text { hemodynamically } \\
\text { stable }\end{array}$ \\
\hline Neurological evaluation & reactive to stimuli & reactive to stimuli & reactive to stimuli & reactive to stimuli & reactive to stimuli \\
\hline Treatment & phototherapy & phototherapy & phototherapy & phototherapy & - \\
\hline
\end{tabular}

in particular on its association to hemolytic disease of the fetus and newborn (HDFN). While some authors found anti-Ku to be associated to severe perinatal anemia, others found no clinical evidence of affected infants [6-11]. On the other hand, anti-Ku-like antibody has been described in individuals whose RBCs are classified as $K_{\text {mod }}$ [12]. In the following case report, we describe the clinical relevance of an anti-Ku found in a $\mathrm{K}_{0}$ puerpera.

\section{Case Report}

A 21-year-old, gravida 2, para 1, Argentinean, blood group A RhD-positive woman was admitted to hospital in labor, at 40 weeks of an unmonitored gestation. The woman did not refer previous abortions nor transfusions and delivered an blood group A RhD-positive baby, who weighed $3,320 \mathrm{~kg}$, had marked hyperbilirubinemia (total bilirubin $6.32 \mathrm{mg} / \mathrm{dl}$ ) and a positive (4+) direct antiglobulin test (DAT). The neonate was immediately treated with phototherapy. Total bilirubin values increased progressively. No compatible RBCs with maternal serum were found for exchange transfusion. Washed maternal RBCs were prepared but not used as total bilirubin began to decrease gradually on day 3 . Table 1 summarizes the evolution and laboratory findings of the newborn during hospitalization.

A peripheral blood sample of the proband was sent to our reference laboratory because of the presence of an IgG RBC alloantibody that reacted (3+) with all panel RBCs in the anti-human globulin phase in low-ionic-strength solution and with papain-modified RBCs. Maternal serum was nonreactive when tested either with dithiothreitol-treated or EDTA/glycine-acid-treated RBCs. The titer of the antibody against her husband's ABO-compatible RBCs was 128. Extended erythrocyte typing was performed using tube technique [13], and the following phenotype was identified: $\mathrm{C}+\mathrm{c}+\mathrm{E}-\mathrm{e}+\mathrm{M}+\mathrm{N}-\mathrm{S}-\mathrm{s}+$; Fy $(\mathrm{a}+\mathrm{b}+)$; $\mathrm{Jk}(\mathrm{a}+\mathrm{b}-) ; \mathrm{Lu}(\mathrm{a}-\mathrm{b}+) ; \mathrm{Le}(\mathrm{a}-\mathrm{b}+) ; \mathrm{K}-\mathrm{k}-; \mathrm{Kp}(\mathrm{a}-\mathrm{b}-) ; \mathrm{Js}(\mathrm{a}-\mathrm{b}-)$. The patient's RBCs typed negative for all Kell blood group antigens studied. DAT and autocontrol were negative by both the conventional tube method and gel test. Altogether these results suggested a potential $\mathrm{K}_{0}$ phenotype with the presence of an
anti-Ku alloantibody. Occasionally, it is difficult to distinguish by serology between a $\mathrm{K}_{0}$ and a $\mathrm{K}_{\text {mod }}$ phenotype. The detection of Kell antigens highly depends on the avidity of reagents being used; therefore, sometimes it is challenging to establish the boundaries between a weakly positive agglutination and a negative one. Considering this, the possibility of a $\mathrm{K}_{\text {mod }}$ phenotype with an anti$\mathrm{Ku}$ like antibody could not be disregarded until molecular investigations are carried out.

$K E L$ genotyping was performed in maternal genomic DNA by polymerase chain reaction (PCR) restriction fragment length polymorphism strategies [14] and showed $K E L^{\star} 02 / 02, K E L^{\star} 04 / 04$ and $K E L^{*} 07 / 07$ genotypes. Because of the discrepancy between serologic and molecular findings, each of the 19 exons of $K E L$ gene and intron-exon boundaries were sequenced using the Sanger dideoxy method [15]. Chromatograms showed a homozygous substitution of a guanine to an adenine at the first nucleotide of Intron 3 (IVS $3+1 \mathrm{~g}>\mathrm{a}$ ) changing the conserved $g t$ sequence at the $5^{\prime}$ splice site to at. This event causes aberrant RNA splicing, altering the reading frame and introducing a premature stop codon that prevents expression of Kell glycoprotein on the RBC membrane [16]. Sequencing data provided by the Exome Aggregation Consortium [17], obtained from 60,706 unrelated individuals of diverse ethnicity showed that the IVS3 + $1 \mathrm{~g}>\mathrm{a}$ mutation (dbSNP accession: rs369569464) [18] has a frequency of $8.29 \times$ $10^{-5}$ and was found in European (non-Finnish), European (Finnish), Latino and South Asian populations. The IVS3 + $1 a$ variant, termed $K E L^{\star} 02 N .06$ allele by the International Society of Blood Transfusion [3], is one of the most frequent genetic bases for the extremely rare $K_{0}$ phenotype [19]. Molecular analysis confirmed that the proband had the $\mathrm{K}_{0}$ phenotype, and it is highly suggested that specificity of the alloantibody found in patient's serum was effectively an anti-Ku.

Proband's family members were investigated by serological and molecular methods in order to provide them with proper counseling regarding alloimmunization after transfusion and/or pregnancy. A PCR with sequencespecific primer (SSP) strategy was developed to detect the mutation found in the proband. Two separate PCRs were performed using a forward primer (ATCTTTCACCTCTTGGTTCCTCCC) complementary to a consensus sequence of the KEL gene paired with reverse primers containing at their $3^{\prime}$ ends (position IVS3 + 1) the polymorphic nucleotides C (GGGGGTCTGGGATCTTGCTTAC) to anneal with $\mathrm{G}$ in the KEL wild type allele or $\mathrm{T}$ 


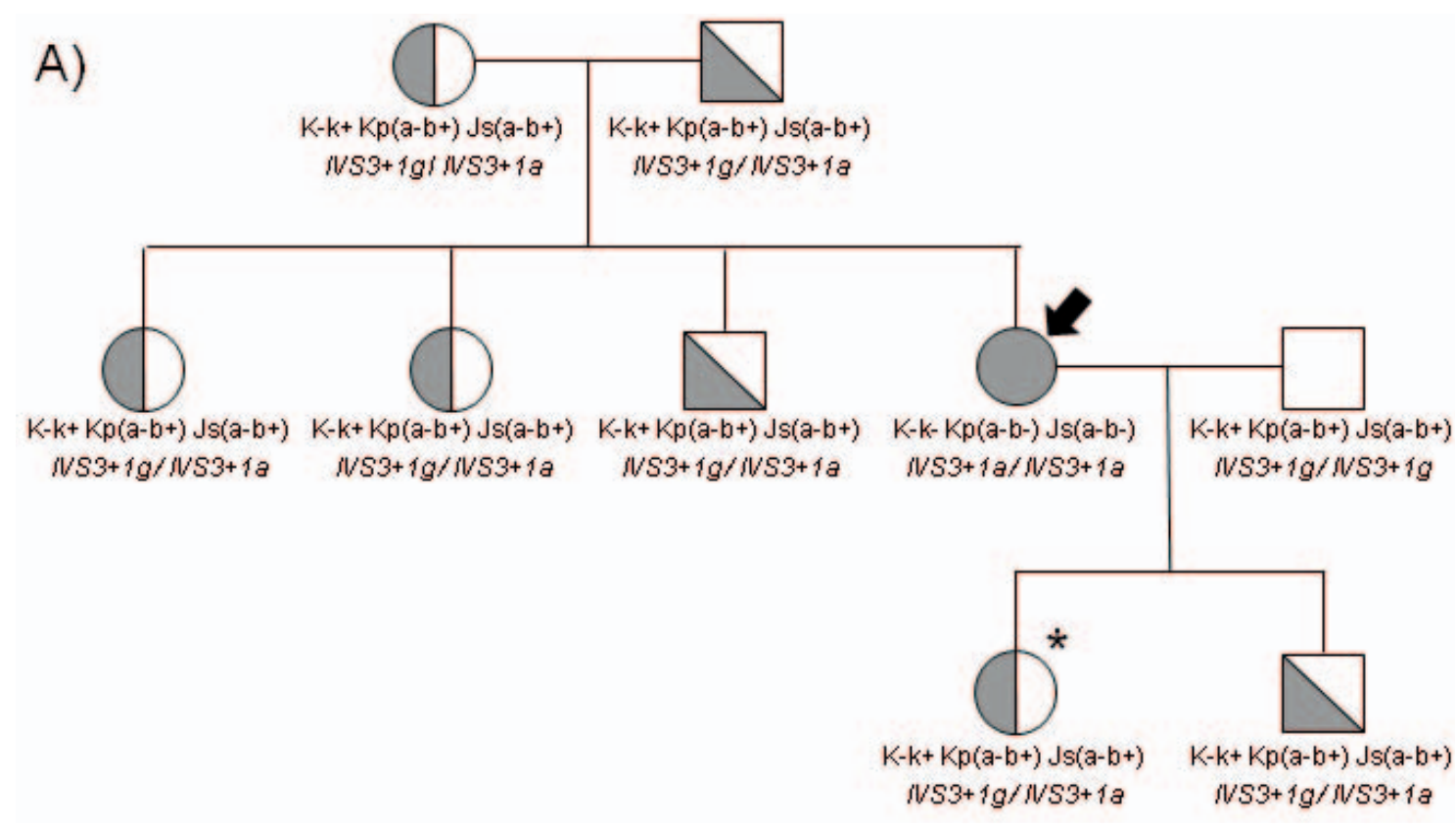

Fig. 1. Serological and molecular analysis in proband's family members. A Pedigree showing Kell antigens phenotyping and $\mathrm{KEL}^{\star} 02 \mathrm{~N}$.06 genotyping results. B Gel electrophoresis showing allele-specific PCR results for the detection of the IVS $3+1 \mathrm{~g}>$ a point mutation $\left(\mathrm{KEL}^{*} 02 \mathrm{~N} .06\right.$ allele). Arrow indicates the proband. Asterisk indicates the newborn affected by HDFN.
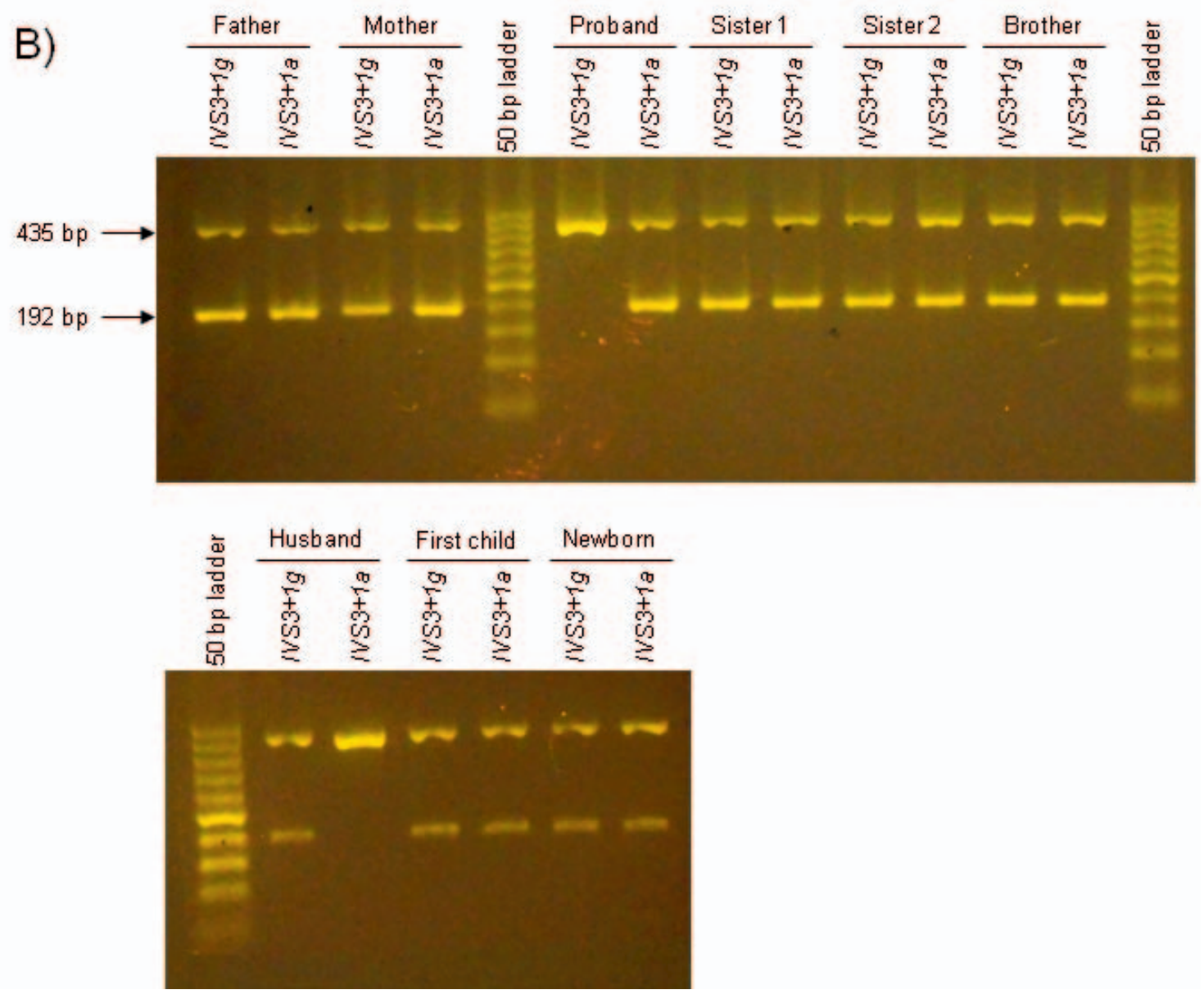

(GGGGGTCTGGGATCTTGCTTAT) to anneal with A in the KEL ${ }^{*} 02 N .06$ allele, in each reaction. To establish optimal PCR conditions, DNA samples from the patient (genotype $K E L^{\star} 02 \mathrm{~N} .06 / K E L^{\star} 02 \mathrm{~N} .06$ ) and a normal individual (genotype $\left.K E L^{\star} 01 / K E L^{\star} 02\right)$ were used. Amplifications were performed with approximately $0.5 \mu \mathrm{g}$ of genomic DNA in a final volume of $10 \mu \mathrm{l}$ containing 0.4 $\mu \mathrm{mol} / \mathrm{l}$ of each primer (except for primers used for internal positive controls that were at $0,04 \mu \mathrm{mol} / \mathrm{l}), 0.2 \mathrm{mmol} / \mathrm{l}$ of each dNTP, $2 \mathrm{mmol} / 1 \mathrm{MgCl}_{2}$ and $1 \mathrm{U}$ of Taq DNA polymerase in appropriate buffer. PCRs started with one cycle of denaturation at $94{ }^{\circ} \mathrm{C}$ for $5 \mathrm{~min}$ and were ended with one cycle of $10 \mathrm{~min}$ at $72{ }^{\circ} \mathrm{C}$ to complete extension. Cycling parameters were 30 cycles of $40 \mathrm{~s}$ at $94^{\circ} \mathrm{C}, 40 \mathrm{~s}$ 
at $67^{\circ} \mathrm{C}$ for annealing, and $40 \mathrm{~s}$ at $72{ }^{\circ} \mathrm{C}$ for extension. In all PCR reactions a pair of primers that amplify a consensus sequence of the human growth hormone gene was used as internal positive control. PCR products ( $435 \mathrm{bp}$ for internal positive control and $192 \mathrm{bp}$ for specific products) were analyzed by electrophoresis on $2 \%$ agarose gels. This strategy allows the detection of the $K E L^{\star} 02 N$.06 allele in double or single dose. Serological and PCR-SSP results (fig. 1) demonstrated that seven family members (mother, father, 2 sisters, 1 brother and 2 sons) express $\mathrm{k}, \mathrm{Kp}^{\mathrm{b}}$ and $\mathrm{Js}^{\mathrm{b}}$ antigens and carry a single dose of the $K E L^{*} 02 N$.06 allele.

\section{Discussion}

Molecular studies performed in the proband's sample allowed the identification of the allele responsible for a $\mathrm{K}_{0}$ phenotype (KEL ${ }^{*} 02 N$.06) in homozygosity and support the conclusion that the specificity of the alloantibody found in the mother was anti-Ku.

Antibodies to antigens in the Kell blood group system are usually IgG and may be involved in hemolytic transfusion reactions and HDFN $[1,2,4]$. Some specificities, like anti-K and anti-Kpa have been associated not only to IgG-mediated destruction of mature RBCs but also to suppression of erythropoiesis by promoting the immune destruction of erythroid early progenitor cells by macrophages in the fetal liver [20,21]. As regards anti-Ku, little is known about its clinical significance due to the fact that sensitized $\mathrm{K}_{0}$ individuals are rare. While some authors described anti-Ku to produce hemolytic transfusion reactions and HDFN, the lack of hemolysis attributed to this specificity has been observed by others [6-11]. In our case, the laboratory findings and clinical course of the newborn were consistent with immune-mediated RBC destruction. The hyperbilirubinemia found in the newborn increased progressively reaching a peak on the 3rd day of life while, concomitantly, hematocrit and hemoglobin values decreased, showing moderate anemia. Taking into account that mother and baby were $\mathrm{ABO}$-identical, the raise in bilirubin values cannot be attributed to $\mathrm{ABO}$ incompatibility but to the action of the anti-Ku alloantibody, which in turn depends on the IgG subclass involved. It is well known that $\operatorname{IgG}_{1}$ and $\operatorname{IgG}_{3}$ interact efficiently with most Fc $\gamma$ receptors on phagocytic cells while $\operatorname{IgG}_{2}$ and $\mathrm{IgG}_{4}$ show reduced affinity to most of them [22]. Consequently, the rate of clearance of sensitized erythrocytes from circulation depends on the IgG subclass of the antibody bound to the RBC membrane. Unfortunately, IgG subclass determination could not be performed, however, clinical and laboratory findings suggest that in our case the hyperbilirubinemia and anemia of the newborn was caused by the immune destruction of RBCs due to $\mathrm{IgG}_{1}$ and/or IgG $\mathrm{Ig}_{3}$ anti-Ku alloantibody. To note, hematocrit and hemoglobin level at birth were normal, and reticulocyte count on day 3 reflected RBC production in re- sponse to anemia. These observations suggest that maternal anti$\mathrm{Ku}$ did not cause a suppressive effect of fetal erythropoiesis during pregnancy, as described for other specificities within the Kell blood group system [20, 21]. Otherwise, parameters associated to RBC production would have been markedly diminished in the newborn.

The baby was briefly treated with phototherapy and discharged home on day 5 in good condition. The anemia of the baby resolved after 4 months without requiring blood transfusion, and hemoglobin remained within the normal range. At 1 year of age, neurological evaluation of the baby was normal, showing no damage caused by hyperbilirubinemia.

We further studied proband's family members so as to provide them with proper counseling regarding transfusion and possible alloimmunization events. Although ABO-compatible with the proband, no $K E L^{\star} 02 N$.06 homozygous individuals lacking Kell antigen expression were found. These findings show that household members are not compatible donors regarding the Kell system. As a result, autotransfusion programs should be implemented in the patient in case of need. Otherwise, a high-risk transfusion protocol indicated only for extreme situations must be followed. Serological and molecular findings enabled us to inform the patient's family members studied, mainly her two sisters, that they are not at risk of developing an anti-Ku.

In summary, our case provides valuable information on serological, molecular, and clinical findings regarding HDFN associated to an anti-Ku alloantibody produced by a $\mathrm{K}_{0}$ pregnant woman. Even though the antibody was directed against the Kell blood group system, the newborn was successfully treated with phototherapy, and no exchange transfusion was needed. Integrated phenotype and genotype studies allowed precise medical recommendations for the proband and her family group.

\section{Ethical Approval}

Written informed consent from the patients was obtained.

\section{Acknowledgement}

We are grateful to Cecilia Siniscalchi for her assistance in laboratory analysis.

\section{Disclosure Statement}

The authors declare that they have no conflicts of interest relevant to the manuscript submitted. 


\section{References}

1 Lee S, Russo D, Redman C: The Kell blood group system: Kell and XK membrane proteins. Semin Hematol 2000;37:113-121.

2 Westhoff CM, Reid ME: Review: the Kell, Duffy, and Kidd blood group systems. Immunohematology 2004; 20:37-49.

3 International Society of Blood Transfusion: Red Cell Immunogenetics and Blood Group Terminology. www. isbtweb.org/working-parties/red-cell-immunogeneticsand-blood-group-terminology/ (last accessed October 11, 2016).

4 Denomme G: Kell and Kx blood group systems. Immunohematology 2015;31:14-19.

5 Boturão-Neto E, Yamamoto M, Chiba AK, Kimura EY, de Oliveira MC, do Monte Barretto CL, Nunes MM, Albuquerque SR, de Deus Santos MD, Bordin JO: Molecular basis of KELnull phenotype in Brazilians. Transfus Med Hemother 2015;42:52-58.

6 Huang HJ, Tagawa H: Hemolytic disease of the newborn due to anti-Ku. Nippon Sanka Fujinka Gakkai Zasshi 1982;34:119-121

7 Fourmaintraux A, Vitrac D, Mariette JB, Brunel F: The $\mathrm{K}_{0}$ phenotype and fetal-maternal alloimmunization. Arch Fr Pediatr 1993;50:779-781.

8 Manoura A, Korakaki E, Hatzidaki E, Saitakis E, Maraka S, Papamastoraki I, Matalliotakis E, Foundouli K, Giannakopoulou C: Use of recombinant erythropoietin for the management of severe hemolytic disease of the newborn of a $\mathrm{K}_{0}$ phenotype mother. Pediatr Hematol Oncol 2007;24:69-73.
9 Lydaki E, Nikoloudi I, Kaminopetros P, Bolonaki I, Sifakis S, Kikidi K, Koumantakis E, Foundouli K: Serial blood donations for intrauterine transfusions of severe hemolytic disease of the newborn with the use of recombinant erythropoietin in a pregnant woman alloimmunized with anti-Ku. Transfusion 2005;45:17911795.

10 Moulds JM, Persa R, Rierson D, Billingsley KL, Noumsi GT, Hue-Roye K, Reid ME. Three novel alleles in the Kell blood group system resulting in the Knull phenotype and the first in a Native American. Transfusion 2013;53(11 suppl 2):2867-2871.

11 Kakaiya RM, Whaley A, Howard-Menk C, Rami J, Papari M, Campbell-Lee S, Malecki Z: Absence of hemolytic disease of fetus and newborn despite maternal high-titer IgG anti-Ku. Immunohematology 2010;26: 119-123.

12 Lee S, Russo DC, Reid ME, Redman CM: Mutations that diminish expression of Kell surface protein and lead to the $\mathrm{K}_{\bmod } \mathrm{RBC}$ phenotype. Transfusion 2003;43: 1121-1125.

13 Roback JD, Grossman BJ, Harris T, Hillyer CD (eds): Technical Manual, 17th ed. Bethesda, American Association of Blood Banks, 2011.

14 Arnoni C, Muniz J, de Paula T, Person RD, Gazito D, Baleotti W Jr, Barreto JA, Castilho L, Latini FR: An easy and efficient strategy for KEL genotyping in a multiethnic population. Rev Bras Hematol Hemoter 2013;35:99-102.
15 Yu LC, Twu YC, Chang CY, Lin M: Molecular basis of the Kell-null phenotype: a mutation at the splice site of human KEL gene abolishes the expression of Kell blood group antigens. J Biol Chem 2001;276:1024710252.

16 Lee S, Russo DC, Reiner AP, Lee JH, Sy MY, Telen MJ, Judd WJ, Simon P, Rodrigues MJ, Chabert T, Poole J, Jovanovic-Srzentic S, Levene C, Yahalom V, Redman CM: Molecular defects underlying the Kell null phenotype. J Biol Chem 2001;276:27281-27289.

17 Exome Aggregation Consortium (ExAC): http://exac. broadinstitute.org (last accessed October 11, 2016).

18 National Center for Biotechnology Information: dbSNP Short Genetic Variations.Database of Single Nucleotide Polymorphisms (dbSNP). www.ncbi.nlm nih.gov/SNP (last accessed October 11, 2016).

19 Wester ES, Storry JR, Schneider K, Nilsson Sojka B, Poole J, Olsson ML: Genetic basis of the K(0) phenotype in the Swedish population. Transfusion 2005;45: 545-549.

20 Daniels G, Hadley A, Green CA: Causes of fetal anemia in hemolytic disease due to anti-K. Transfusion 2003; 43:115-16.

21 Tuson M, Hue-Roye K, Koval K, Imlay S, Desai R, Garg G, Kazem E, Stockman D, Hamilton J, Reid ME: Possible suppression of fetal erythropoiesis by the Kel blood group antibody anti-Kpa ${ }^{\mathrm{a}}$. Immunohematology 2011;27:58-60.

22 Bruhns P, Iannascoli B, England P, Mancardi DA, Fernandez N, Jorieux S, Daëron M: Specificity and affinity of human Fcgamma receptors and their polymorphic variants for human IgG subclasses. Blood 2009;113 3716-3725. 